\title{
Quantifying Vadose Zone Flow and Transport Uncertainties Using a Unified, Hierarchical Approach
}

(Project Number: 70187)

\section{Principal Investigator}

Philip D. Meyer

Pacific Northwest National Laboratory

Battelle Portland Office

Portland, OR

503-417-7552 (phone)

503-417-2175 (fax)

philip.meyer@pnl.gov

\section{Co-Investigators}

Chris J. Murray

Pacific Northwest National Laboratory

P.O. Box 999, MSIN K6-81

509-376-5848 (phone)

509-376-5368 (fax)

chris.murray@pnl.gov

Mark L. Rockhold

Pacific Northwest National Laboratory

P.O. Box 999, MSIN K9-33

541-737-5410 (phone)

rockhold@engr.orst.edu

\section{Graduate Student}

Marcel Schaap, post-doctoral 


\section{Research Objective}

The objective of this research is to develop and demonstrate a general approach for modeling flow and transport in the heterogeneous vadose zone. The approach uses similar media scaling, geostatistics, and conditional simulation methods to estimate soil hydraulic parameters at unsampled locations from field-measured water content data and scale-mean hydraulic parameters determined from available site characterization data. Neural network methods are being developed to estimate soil hydraulic parameters from more easily measured physical property data such as bulk density, organic matter content, and percentages of sand, silt, and clay (or particle-size distributions). Field water content distributions are being estimated using various geophysical methods including neutron moderation, ground-penetrating radar, and electrical resistance tomography. One of the primary goals of this research is to determine relationships between the type of data used in model parameterization, the quantity of data available, the scale of the measurement, and the uncertainty in predictions of flow and transport using these methods. Evaluation of the relationships between available data, scale, and uncertainty will use primarily existing data from large-scale, controlled experiments.

\section{Research Progress and Implications}

This report summarizes work completed after 1.5 years of a 3-year project. A large-scale injection experiment was conducted in summer 2000 as part of another project, on the Hanford Site where a previous injection experiment had been conducted in 1982. The site was already instrumented from the 1982 experiment with thirty-two 18-m-deep wells arranged radially around a central injection well. Various other types of instrumentation were installed as part of a separate project for the experiment conducted in 2000. These instruments included access tubes of polyvinyl chloride to provide access for cross-borehole ground-penetrating radar (GPR), tensiometers for measurement of soil water pressure head, and other equipment. Six separate injections of water were made during the experiment, at a depth of approximately $4.6 \mathrm{~m}$ below ground surface. The instruments described above were used to quantify the dynamics of the water plume.

Prior to the injections, three additional boreholes were emplaced at the site, and core samples were collected from these boreholes using a split-spoon sampler as part of our EMSP project. Subsamples were collected from approximately 60 of these cores. These subsamples were used to determine bulk densities, porosities, particle-size distributions, water retention characteristics, saturated hydraulic conductivities, and unsaturated hydraulic conductivities at the U.S. Salinity Laboratory in Riverside, California. These data and other physical and hydraulic property data sets from the Hanford Site are being used in neural network analyses to develop correlations and so-called pedotransfer functions to relate the more easily determined physical property data to the measured hydraulic properties at the site. The data also have been used to estimate hydraulic property model parameters and parameter distributions and for scaling analyses to estimate scalemean hydraulic parameters for use in numerical modeling of the injection experiment. 
In 1995, Schlumberger well-logging services logged the 32 wells at the experimental site using various tools, including neutron probes and a litho-density sonde (LDS), for estimating water content and wet density, respectively. The LDS data were collected at $2.5-\mathrm{cm}$-depth intervals to a depth of approximately $18 \mathrm{~m}$. Neutron probe data from the experiment conducted in 2000 were collected at $30-\mathrm{cm}$-depth intervals. The revised LDS data were reanalyzed and correlated with the neutron probe data so that the LDS data can be used to estimate both water contents and porosities at the $2.5-\mathrm{cm}$-depth resolution. The spatial auto- and cross-correlation structures of the initial (pre-injection) water content and porosity data are being analyzed for use in the development of high-resolution geostatistical models of the water content and porosity distributions at the site. Conditional simulations of the water content and porosity fields will be generated using sequential Gaussian or indicator simulation methods. The generated fields will span a domain that is $20-\mathrm{m}$ wide on each side and $12-\mathrm{m}$ deep. This domain will be discretized with approximately 3 million nodes.

\section{Planned Activities}

The high-resolution water content and porosity fields will be used in conjunction with the scalemean hydraulic properties determined from the core samples to parameterize a three-dimensional flow and transport model (STOMP90). This model will then be used to simulate the field experiment. The high-resolution model results will be used as a reference for comparison with results obtained using upscaled model parameters and for alternative parameterizations based on the neural network analyses and other types of data. The results from these simulations will be compared to evaluate the relationships between the type of data used in model parameterization, the quantity of data available, the scale of the measurement (or grid block size), and the uncertainty in predictions of flow and transport using these methods.

\section{Information Access}

Details regarding the field experiment and geophysical data used for model parameterization and testing can be found at http://etd.pnl.gov:2080/vadose/. 